\title{
International symposium on aquaculture, biology and management of commercially important crabs, Shanghai (China), 8-11 November 2009 (ISABMC-2009)
}

\author{
Lewis Le Vay $\cdot$ Colin Shelley $\cdot$ Chaoshu Zeng $・$ Patrick Sorgeloos
}

Published online: 11 March 2011

(C) Springer Science+Business Media B.V. 2011

Over recent decades, crab aquaculture has emerged as a new industry, driven by increasing market demand and collapses of crab stocks and fisheries worldwide. Building on symposia previously held in Australia, the Philippines and Vietnam, the ISAMBC-2009 meeting brought together international crab scientists and industry to share insights into crab aquaculture, biology and resource management and to highlight future research needs for the sustainable development of crab aquaculture. The symposium was hosted at the new campus of Shanghai Ocean University. Over the last 20 years, Chinese mitten crab farm production in China has grown from just over 3,000 tonnes to over 500,000 tonnes per annum. In addition, China is now the largest producer of farmed mud crabs, Scylla spp., and the swimming crab, Portunus trituberculatus, at over 106,000 tonnes and 100,000 tonnes per annum, respectively. Vietnam has also reported impressive growth in mud crab aquaculture production from just 3,000 tonnes in 1995 to an estimated 30,000 tonnes per annum, with one-third of this production based on crablets produced in hatcheries. In the Philippines also, hatchery production of mud crabs is increasing, with private hatcheries now using technology developed by the South East Asian Fisheries Development Centre and the University of the Philippines Visayas. The symposium highlighted-in addition to the rapid growth in production of the major farmed crab species-the increasing number of species of crab currently being cultured. Another exciting revelation from the meeting was that a number of successful stock enhancement trials of various crab species have now taken place around the world (USA, Japan, Philippines, Vietnam), demonstrating the potential for hatchery-produced crab stock to

L. Le Vay $(\bowtie)$

Bangor University, Bangor, UK

e-mail: 1.levay@bangor.ac.uk

C. Shelley

YH \& CC Shelley Pty. Ltd, Brisbane, Australia

C. Zeng

James Cook University, Townsville, Qld 4811, Australia

P. Sorgeloos

Ghent University, Ghent, Belgium 
successfully support the recovery of wild stocks. A concluding workshop identified the following important themes for further consideration and action: sustainability of both crab fisheries and farming systems; domestication of stocks for farming; hatchery technology; development of specialised crab feeds; techniques to reduce cannibalism of crabs during grow-out; disease management; and economic analysis to drive future research. The ISAMBC also highlighted the need for concerted international collaboration in research, farming technology and fisheries management to optimise the benefits of the world's crab resources within an ecologically sustainable development framework. Mitten crab farming in China is mostly conducted at low stocking densities, often integrated with other land use, over very large areas of coastal and inland wetlands. In the case of mud crabs, growth in production has largely been made using low-density farming systems, often in smallscale farms using integrated systems involving polyculture and mangrove silviculture and has so far avoided the widespread disease problems typically associated with intensification. The symposium's scientific committee urged that the sustainable expansion of crab culture should include responsible approaches to integrated management of coastal ecosystems to prevent the environmental problems that have developed with intensive and widespread culture of other species.

\section{Organizing committee}

Honorary Chairmen: Prof. Yingjie Pan, President, Shanghai Ocean University, and Prof. Jianhai Xiang, President, Chinese Crustacean Society.

Conference Chairmen: Prof. Yongxu Cheng, Shanghai Ocean University, China, and Prof. Patrick Sorgeloos, Ghent University, Belgium.

Co-Chairmen: Dr. Chaoshu Zeng, James Cook University, Australia, and Dr. Lewis Le Vay, Bangor University, UK. 